\title{
CONSUMO DE DROGAS PELOS ADOLESCENTES NAS ESCOLAS MOÇAMBICANAS: ESTRATÉGIAS DE INTERVENÇÃO PSICOSSOCIAL
}

\author{
Rosário Martinho Sunde ${ }^{1}$
}

\begin{abstract}
RESUMO: O presente artigo, com o tema o consumo de drogas pelos adolescentes nas escolas moçambicanas: estratégias de intervenção psicossocial com alunos das escolas da cidade de Nampula, visa analisar as implicações do consumo de álcool e outras drogas pelos alunos no recinto escolar e propor estratégias de mitigação sobre o consumo das drogas nas escolas. O estudo parte duma experiência profissional do autor que durante as atividades de estágios e práticas pedagógicas com estudantes de Psicologia Educacional na Universidade Pedagógica de Moçambique, Delegação de Nampula, em algumas escolas daquela cidade, pôde identificar que, em algumas aulas, os alunos estavam sob efeito de drogas. Outrossim, a motivação pelo estudo se sustenta pelas frequentes notícias e atenção do Governo pelo fenômeno em algumas escolas do país. Estrategicamente, o estudo levanta desafios para desencorajar e até estancar a situação.
\end{abstract}

Palavras-chave: Drogas. Adolescente. Escola.

\section{DRUG USE BY ADOLESCENTS IN MOZAMBICAN SCHOOLS: STRATEGIES OF PSYCHOSOCIAL INTERVENTION}

\begin{abstract}
This article, with the theme of drug use by adolescents in Mozambican schools: strategies of psychosocial intervention with students from schools in the city of Nampula, aims to analyze the implications of alcohol consumption and other drugs by students in the school and propose strategies of mitigation of drug use in schools. The study is based on a professional experience of the author who during the internship activities and pedagogical practices with students of Educational Psychology at the Pedagogical University of Mozambique, Nampula Delegation, in some schools of that city, identified that in some classes, the students were under drug effects. Also, the motivation for the study is sustained by the frequent news and attention of the Government by the phenomenon in some schools of the country. Strategically, the study raises challenges to discourage and otherwise staunch the situation.
\end{abstract}

Keywords: Drugs. Adolescent. School.

\footnotetext{
${ }^{1}$ Mestre em Administração e Gestão Escolar. Doutorando em Psicologia na Pontifícia Universidade Católica do Rio Grande do Sul-Brasil (PUCRS) Porto Alegre-RS/Brasil. Docente da Universidade Pedagógica Nampula/Moçambique. E-mail: rsundescanda@gmail.com
} 


\section{CONSUMO DE DROGAS POR ADOLESCENTES EN ESCUELAS MOZAMBIQUEÑAS: ESTRATEGIAS DE INTERVENCIÓN PSICOSOCIAL}

RESUMEN: El presente artículo, con el tema el consumo de drogas por los adolescentes en las escuelas mozambiqueñas: estrategias de intervención psicosocial con alumnos de las escuelas de la ciudad de Nampula, busca analizar las implicaciones del consumo de alcohol y otras drogas por los alumnos en el recinto escolar y proponer estrategias de intervención y mitigación sobre el consumo de drogas en las escuelas. El estudio parte de una experiencia profesional del autor que, durante las actividades de prácticas con estudiantes de Psicología Educacional en la Universidad Pedagógica de Mozambique, Delegación de Nampula, en algunas escuelas de aquella ciudad, pudo identificar que, en algunas clases, los alumnos iban bajo efecto de drogas. Además, la motivación por el estudio se sustenta por las frecuentes noticias y atención del Gobierno por el fenómeno en algunas escuelas del país. Estratégicamente, el estudio plantea desafíos para desalentar y hasta detener la situación.

Palabras clave: Drogas. Adolescente. Escuela.

O consumo de drogas pelos adolescentes e jovens nas escolas tende a ganhar proporções cada vez maiores em muitas escolas nas grandes cidades moçambicanas. É habitual observar-se alunos sob efeito de álcool e outras drogas no recinto escolar e em particular, na sala de aula. Essa atitude, muitas vezes, conduz ao consumidor um comportamento agressivo, interferindo no percurso normal do processo de ensino e aprendizagem e ou ainda, baixo aproveitamento do mesmo.

O consumo de álcool e outras drogas, enquanto adolescente, pode criar danos no Sistema Nervoso Central (SNC) e o organismo passa a depender dessa substância no exercício das suas funções. Como docente da Universidade Pedagógica Moçambique, Delegação de Nampula, o autor fez muitas visitas, práticas pedagógicas e psicológicas, estágios com estudantes do Curso de Psicologia e se apercebeu que:

- Em muitas escolas, adolescentes participavam das aulas sob efeito de álcool e outras drogas;

- Ao redor do recinto de algumas escolas estavam construídas barracas e cantinas vendendo álcool e outras drogas;

- Havia muita indisciplina e incumprimentos do regulamento e normas escolares pelos alunos; 
- Registo de agressões, roubos e assaltos protagonizados pelos adolescentes;

- Registo de desistências e abandono escolar pelos adolescentes;

- Inexistência de serviços sociais e de aconselhamento psicológico nas escolas para ajudar na orientação dos adolescentes;

- Inexistência de políticas claras de desencorajamento de consumo de álcool e drogas pelos adolescentes nas escolas.

- Falta de divulgação da Resolução n¹5/2003, de 4 de abril, Política e Estratégia de Prevenção e Combate a Drogas, aprovada pelo Conselho de Ministros da República de Moçambique.

A respeito dessa matéria, a Resolução $n^{\circ} 15 / 2003$ de 4 de Abril, nas suas alíneas a e b, do número 4.2 (p. 156) sustenta que entre tantos objetivos explícitos, é preocupação do Governo: "assegurar uma melhor informação da sociedades e educação moçambicana sobre a perigosidade do consumo ilícito de drogas e, reduzir o consumo ilícito de drogas no seio da camada juvenil e nas escolas".

Recentemente, no Jornal Notícias Online (MOÇAMBIQUE, 2016), publicado em 23 março de 2016; o então Ministro da Educação e Desenvolvimento Humano, Jorge Ferrão defendeu que o combate ao consumo excessivo do álcool e drogas por parte dos adolescentes e jovens nas escolas deveria envolver todas as forças vivas da sociedade civil, com particular destaque para pais e encarregados, professores e gestores escolares. $\mathrm{O}$ apelo foi quando do lançamento do projeto "smahsed" (quebrados) que visa despertar os riscos sobre o consumo de álcool e drogas na menor idade, no seio da camada estudantil na faixa dos 12 aos 13 anos.

A iniciativa promovida pela $\mathrm{DIAGEO}^{2}$ em parceria com o Ministério da Educação e Desenvolvimento da Humano e o Consulado Britânico em Moçambique, pretende divulgar mensagens educativas por meio de peças teatrais nas escolas onde serão abordados os impactos negativos do consumo de bebidas alcoólicas e outras drogas. No seu discurso o Ministro da Educação enfatizou que os atuais níveis de consumo de álcool e outras drogas são preocupantes pois para além de criar sérios riscos a saúde dos alunos, comprometem o seu aproveitamento pedagógico.

\footnotetext{
2 Empresa de bebidas do Reino Unido, fundada em 1997, é a maior fabricante de bebidas destiladas do mundo, ela vende seus produtos em 180 países e tem representações em 80 países. Em 2014, a empresa empregava mais de 36.000 pessoas e a sua sede fica na cidade de Londres.
} 
"O álcool, o vírus da imunodeficiência humana (HIV), o tabaco e outras drogas são males sociais que ameaçam destruir a juventude de numerosos alunos pelo país, e isto é um chamamento a união de todas as forças vivas da sociedade para que possamos enfrentar e erradicar estes males de modo a proteger as gerações vindouras destes perigos" alertou o Ministro.

A exposição que os alunos encontram pelo fato de algumas escolas estarem próximas de mercados informais onde se vendem bebidas alcoólicas e outras drogas, Jorge Ferrão pediu uma maior responsabilidade por parte dos agentes informais, chamando estes a serem parceiros do Ministério da Educação na erradicação do fenômeno.

Naturalmente temos barracas em volta das nossas escolas, nos espaços que foram tomados pelo comércio informal. Respeitamos as pessoas que exercem o comércio informal, mas gostaríamos, com eles fazer um pacto e apelar que somente vendam o álcool a maiores de 18 anos e não as crianças, pois a nossa área de jurisdição é até o limite da própria escola (MOÇAMBIQUE, 2016).

Moçambique é o primeiro país africano a acolher essa iniciativa que surgiu no Reino Unido há sensivelmente 11 anos, tendo já escalado diversos países como a Irlanda, Vietnã, Jamaica, entre outros. Na primeira faz, e o projeto vai abranger 45.000 alunos de 30 escolas do Distrito de Marracuene, onde atores profissionais da Escola de Comunicação e Artes (ECA) vão escalar duas escolas por dia.

Ainda, em notícias de 10 de Novembro de 2015 , apontam que na província do norte de Moçambique (Nampula), mais de cinco mil alunos e professores foram encontrados a consumir drogas e bebidas alcoólicas nos recintos escolares. Autoridades prometem regras mais duras. Nessa mesma fonte, o psicólogo Francisco Armando alertou para os perigos do consumo de drogas. Pediu a intervenção do Governo para acabar com esse fenômeno, implementando políticas claras. "O álcool, como outras drogas, pode alterar o funcionamento normal do nosso cérebro, dando-nos um comportamento não desejável. As escolas constroem o homem, se este homem começa a consumir álcool a partir dela, a situação pode complicarse, futuramente", considera.

A título de exemplo, a fonte apresenta-nos narrativas de alguns alunos consumidores de drogas que pensamos em não identificá-lo pelo nome, codificá-lo em Aluno A. Esse aluno disse que frequentava a $12^{\mathrm{a}}$ classe na Escola Secundária de Nampula e consumia álcool desde 
dezembro de 2011. Ele disse que o álcool era a única forma de combater o estresse. "Se for uma sexta-feira posso beber até cair. Eu bebo mesmo", afirma. O aluno conhecia os perigos de beber álcool em excesso, mas disse que não via outra alternativa. Aos outros jovens deixou um conselho: "bebam com moderação. Eu não bebo de forma moderada".

Nos últimos anos, registrou-se um aumento no consumo de cannabis, tabaco e álcool nas escolas de Nampula. Este ano, registaram-se mais de cinco mil casos de alunos e professores encontrados a consumir drogas e bebidas alcoólicas em recintos escolares, segundo um relatório da Direção Provincial de Educação e Desenvolvimento Humano, divulgado em outubro de 2015. O documento revela ainda que 100 professores ficaram incapacitados de dar aulas devido a perturbações mentais.

Essa fonte aponta que o relatório, que resulta de um inquérito feito em quase todos os 23 distritos da província de Nampula, no norte de Moçambique, não detalha as causas do consumo de drogas, mas os estudantes dizem que esta é uma forma de aliviar o estresse originado pelo desemprego, além dos salários baixos dos docentes. André Janna, secretário Provincial do Sindicato Nacional dos Professores, lamenta a situação e insta o sector a combater o consumo de drogas. "O consumo de álcool e outros estupefacientes é um dos graves exemplos de educação. Há professores que consomem com os seus alunos", explica.

Segundo o site de notícias moçambicano, Portalangolap (2018), o último relatório do Gabinete Central de Prevenção e Combate a Drogas, as autoridades sanitárias garantem ter atendido um total de 4.240 pacientes com perturbações mentais e comportamentais devido ao consumo de substâncias psicoativas. Como se pode perceber, o problema de álcool e drogas nas escolas moçambicanas, e em Nampula em particular, constitui uma preocupação das autoridades governamentais, das direções das escolas, dos encarregados de educação e do autor, com ansiedade de ver o desenvolvimento de personalidade dos alunos/cidadãos conforme os anseios e princípios socialmente aceites.

\section{Abordagem Epidemiológica do consumo do álcool}

Na abordagem sobre esse assunto Willhelm et al. (2015, p. 209) sustenta que: "o uso e abuso de álcool e outras drogas estão cada vez mais frequentes entre os adolescentes e isso pode acarretar problemas posteriores na vida do indivíduo, como a dependência de 
substâncias" Para Almeida et al. (2014, p. 66),

O consumo exagerado de álcool e de outras drogas na adolescência pode causar alterações neurofisiológicas profundas, causando graves danos à memória, ao aprendizado, à inteligência, à capacidade de abstração além de aumentar a propensão dos jovens ao alcoolismo.

Para Martins e Quadros (2013), o consumo de bebidas alcoólicas por crianças e adolescentes pode levar a consequências graves, pois, eles ainda não atingiram o nível de desenvolvimento dos adultos, na maturidade social, na experiência de vida ou no desenvolvimento neuropsicológico. Assim, a escola e a família são órgãos relativamente importantes na promoção da saúde estudantil, difundindo informações contra o consumo de drogas pelos adolescentes e jovens na escola e fora dela. Tais entidades funcionam como camada protetora e devem-se envolvem na prevenção e educação dos adolescentes, demonstrando seus efeitos nocivos.

Portanto, o consumo de álcool e outras drogas pelos adolescentes traz consigo inúmeras consequências que são visíveis tais como: complicação de saúde, baixo aproveitamento pedagógico, a disseminação do HIV/SIDA com ato sexual desprotegido, o que origina gravidez indesejada e Doenças de Transmissão Sexual (DTS) e desordem escolar e familiar, comportamento antissocial, perturbador e agressivo, sensíveis para o arranque e/ou o agravamento da dependência.

Nesse sentido, os adolescentes que consomem o álcool e outras drogas consideramnas fator impulsionador que facilitam nas interações sociais, ajudam aos divertimentos, proporcionam melhor aprendizagem, embora tenham o conhecimento dos seus efeitos. Silva (2010), nas suas abordagens sobre consumo de bebidas alcoólicas por estudantes do ensino médio e características do grupo de pares, concebe o álcool como droga mais utilizada no mundo. Desde a antiguidade, está presente em rituais religiosos e festas; no mundo colonial, o vinho era consumido regularmente nas missas e não poderia faltar nos encontros amorosos, além de estar associado a hábitos alimentares. Atualmente, quase todos os países do mundo, onde o consumo é aceito, possuem uma bebida típica da qual se orgulham. No Brasil, apesar de a cerveja ser a bebida mais consumida, a produção de aguardente a partir da cana de açúcar faz parte da história dos brasileiros.

A autora continua afirmando que nas grandes navegações dos séculos XVI e XVII, as 
principais riquezas buscadas no Oriente e na Américas eram drogas. Os homens desse período denominaram as especiarias da Índia oriental como a pimenta, a canela, a noz moscada e o pau brasil, e da Índia Ocidental como o açúcar e o tabaco.

Para Carneiro (2005, p. 11), a palavra droga vem do termo holandês droog que significa produtos secos, e nos séculos XVI e XVIII, representavam "um conjunto de substâncias naturais utilizadas, sobretudo, na alimentação e na medicina". E foram essas substâncias o estímulo para as grandes viagens pelo velho mundo e, a partir delas, as trocas, ou escambos, tornaram-se importantes moedas de troca entre colonizadores e colonizados.

No Brasil, o pau brasil, o açúcar, o algodão e o tabaco abasteciam a colônia, tais especiarias, como eram conhecidas, significavam para os europeus da época fontes de boa saúde para o corpo, disposição dos sentidos e prorrogação da duração da vida, além de garantia de boas vestimentas e colorido nos tecidos. Na época colonial, não se fazia uma diferenciação entre droga e comida, alimento e remédio e as substâncias eram valorizadas, tanto pelas qualidades nutritivas, quanto pelas medicinais, afirma a autora.

\begin{abstract}
Atualmente, a Organização Mundial da Saúde considera como droga qualquer substância não produzida pelo organismo, com propriedade de atuar sobre um ou mais de seus sistemas, produzindo alterações em seu funcionamento. Dessa forma, existem substâncias usadas com a finalidade de produzir efeitos benéficos, como no tratamento de doenças e são consideradas medicamentos e também existem substâncias que provocam malefícios à saúde, os chamados tóxicos (NICASTRI, 2008 apud SILVA, 2010, p. 17).
\end{abstract}

As drogas usadas para alterar o funcionamento do cérebro, causando modificações no estado mental, são chamadas drogas psicotrópicas ou substâncias psicoativas e, em geral, têm a capacidade de provocar dependência. As drogas podem ser classificadas de diferentes formas, uma delas é do ponto de vista legal, as lícitas (comércio livre ou controlado) e outra, as ilícitas, mas também é possível classificá-las do ponto de vista médico, de acordo com as ações aparentes sobre o sistema nervoso central, desta forma há as depressoras, os estimulantes e as perturbadoras (SILVA, 2010).

Na visão de Almeida et al. (2014), o álcool é uma das substâncias psicoativas mais consumidas pelos jovens e de consumo mais precoces, independente da classe econômica ou cultural. Diferentes estudos confirmaram que o álcool pode ser facilmente obtido devido à 
frequente propaganda, o que reflete seu consumo precoce e disseminado. Para esses autores, a população jovem é vulnerável às consequências negativas e, muitas vezes, trágicas do uso de bebidas alcoólicas.

Portanto, a adolescência constitui uma etapa muito complexa no desenvolvimento humano, precisando de um acompanhamento cuidadoso dos pais, dos professores e outras individualidades que fazem parte na vida, por ser uma camada que facilmente desvia-se por este ou aquele motivo. A publicidade nos órgãos de comunicação social - nos canais televisivo, rádio, cinema, imprensa - e placas publicitárias, ligadas ao álcool condicionam aderência de jovens a pensarem que por um lado beber está na moda e por outro é benéfico.

O fabrico em grande quantidade de diversos tipos de bebidas alcoólicas que levam aos adolescentes e jovens a facilidade de obtenção desta substância, vendida quer formalmente: nos supermercados, lojas de bebidas etc., quer informalmente: nas esquinas e barracas próximas aos estabelecimentos de ensino, promove o acesso destas drogas aos adolescentes. Apesar do Decreto Ministerial no 54/2013, de 07 de Outubro, a venda do álcool aos menores de 18 anos ao nível do país, infelizmente, ainda acontece em locais próximos das escolas aos adolescentes e jovens.

Cavalcante, Alves e Barroso (2008, p. 557) enfatizam que:

\begin{abstract}
Além do estímulo constante dos meios de comunicação e da condescendência dos pais, podemos mencionar outros fatores de risco que viabilizam o acesso dos adolescentes a essas substâncias, como sua grande disponibilidade, principalmente de drogas lícitas, em estabelecimentos comerciais e a falta de fiscalização adequada para sua venda, sendo comum a compra por menores de 18 anos; as normas sociais, que estimulam o hábito de "beber socialmente" ou fumar por "ser elegante"; o baixo preço de algumas dessas drogas, o que torna sua aquisição possível à maioria da população; e, por fim, em conflitos familiares graves, quando o adolescente se utiliza desse artifício como fuga à situação.
\end{abstract}

Baptista (2004) refere que as bebidas alcoólicas têm uma longa história. A sua origem remonta provavelmente ao neolítico, quando o homem começou a armazenar em recipientes de cerâmica produtos como o mel, frutas, sementes e cereais, ricos em hidratos de carbono. Da sua decomposição (processo de fermentação) surgiram bebidas de teor alcoólico. No antigo Egito e na Babilónia teria nascido a partir do processo de fermentação de cereais a(s) 
cerveja(s). O hábito de beber cerveja estendeu-se pela bacia mediterrânica desde a Grécia à Ibéria.

A cultura da vinha e a produção de vinho também se perde no tempo, mas sem dúvida que se deve aos gregos e aos romanos na sua difusão, tendo mesmo os seus próprios deuses - Dionísio deus grego e Baco deus romano. Com a queda do Império Romano, a tradição de produzir vinho ficou limitada aos mosteiros - os bárbaros eram bebedores de cerveja - que mantiveram a tradição da cultura da vinha e difundiram as virtudes medicinais do vinho.

O processo de destilação do álcool foi conhecido nos países orientais vários anos antes de Cristo. O descobrimento do alambique atribui-se a um alquimista persa chamado Ramsés, no século VIII a.C. A destilação permite obter bebidas alcoólicas de alta graduação por meio da aplicação de calor a bebidas alcoólicas fermentadas, como é o caso das aguardentes, do cognac, do wisky e da vodka (BAPTISTA, 2004).

O mesmo autor continua argumentando que a palavra álcool tem origem árabe de alkoholo kuhl que originariamente significava "pó fino". Os árabes acreditavam que a embriaguez se devia a um pó que se desprendia das bebidas alcoólicas e que era inalado ao beber; mais tarde alkoho passou a significar "a essência" de uma coisa. Na China, Ceilão, no Cáucaso e no Japão também se fabricavam diferentes tipos de bebidas destiladas a partir dos produtos da fermentação do arroz, do milho e da seiva da palmeira. As bebidas alcoólicas foram utilizadas como anestésicos, analgésicos e euforizantes para combater doenças como a peste negra no século XIV.

O consumo de bebidas alcoólicas conheceu lentamente o aumento a partir no período da Revolução Industrial, quando foram possíveis a divulgação e a comercialização à população mais ampla e para outros lugares ao nível geográfico. Mais tarde, depois do período das descobertas, em conexão da colonização do Mundo Novo, grandes movimentos comerciais surgiram da Europa e nas Américas.

\section{Algumas Teorias Psicológicas sobre o consumo de álcool e outras drogas}

As abordagens psicológicas destacam duas correntes explicativas da dependência no sujeito: A primeira corrente é fundamental na organização e funcionamento do indivíduo a procura do álcool. Esse funcionamento desempenha para o indivíduo o objeto substituto 
privilegiado, num histórico evolutivo de uma personalidade pré-mórbida oral e narcísica. Desse modo, o alcoolismo e outras drogas para os psicanalistas são um sintoma, manifestação de um conflito não resolvido. A segunda corrente é a comportamental - Watson, Skinner, Miller - que defende que o alcoolismo deixa de ter o significado de sintoma para constituir ele próprio a doença, sinônimo de comportamento inadaptado e mal aprendido e, por conseguinte, patológico. O álcool, tornado agente habitual de redução de tensão e ansiedade, de produção de alívio e bem-estar, constitui reforço para a persistência e repetição do comportamento alcoólico (SOUSA, 2008).

A perspectiva psicanalítica, como estratégia de sobrevivência, propôs uma base possível para dar uma explicação sobre o alcoolismo e um modelo global do funcionamento da psique. O prazer como princípio de Freud, desenvolve a inconsciência como sendo qualquer conduta que tem como origem a excitação desagradável e tendo como objetivo, evitar o desprazer ou produzir o prazer e a redução da dita excitação, com o que muitos drogados vêm se desculpando.

Freud definiu a pulsão como um conceito limite entre o anímico e o somático, entre o mental e o biológico. E o objeto da pulsão, neste caso não exclusivamente sexual, é a "coisa", na qual ou por meio da qual a pulsão pode alcançar a sua satisfação e o bem estar do sujeito. O objeto da pulsão não tem um significado puramente existencial, uma vez que pode não se reduzir apenas a uma coisa ou a uma pessoa, mas pode abranger também certos conteúdos inconscientes que tornam presente o objeto apenas representado. É para o objeto representado o álcool, no caso presente que toda a pulsão alcoólica converge. A fixação da pulsão num objeto como o álcool resulta do fato de o álcool poder ser representado como o meio através do qual a pulsão procura satisfazer-se (SOUSA, 2008).

Segundo Rousseau apud Sousa (2008), a neurose seria o resultado de um conflito entre o Ego e o Id. É uma característica do conflito intrapsíquico em que o Ego reprime o Id. O Id é totalmente inconsciente, funcionando segundo o princípio do prazer; desconhece o tempo, as relações causais, a lógica e a sucessão do bom e do mau.

Por sua vez, a psicose seria o resultado de um conflito entre o Ego e o mundo exterior, levando a uma clivagem no seio do Ego, originando um Ego perverso, o qual provoca a dissociação do Ego consciente e de todas as suas funções: o princípio da realidade, a 
socialização, o raciocínio, a adaptação à realidade. De uma forma geral, o álcool produz efeitos distorcidos à percepção da realidade ligado na avaliação errada nas próprias capacidades físicas do indivíduo. Verifica-se uma diminuição da rapidez no indivíduo sobre os seus reflexos cerebrais e os movimentos corporais coordenados ficam comprometidos, o que poderá atingir até a fase de aniquilamento no sentido total da pessoa.

A experiência avançada sobre o álcool tem um efeito calmante e eufórico que na evolução do alcoolismo são consideradas determinantes e com relevância a embriaguez. 0 indivíduo que usa o álcool até chegar à dependência, durante a abstinência, e pelo desejo da manifestação do Ego perverso é levado ao desprazer. O efeito produzido pelo álcool, num adolescente poderá evitar esse desprazer.

\section{Fatores que motivam os adolescentes e jovens a consumirem o álcool e outras drogas}

Realmente não existe uma única causa que possa explicar o porquê de os adolescentes chegarem a consumirem o álcool e outras substâncias psicoativas. Eles se envolvem nas bebidas alcoólicas e outras drogas, por ver todos os amigos a consumirem (pressão de grupos de pares), imitação comportamental, ou por estar na moda, para relaxar, experimentação, fuga de problemas familiares e sociais ou para se sentirem aliviados.

Sousa et al. (2008, p. 47) sublinham que mesmo que não se deva generalizar a influência dos outros sobre os adolescentes, no que se refere ao consumo de bebidas alcoólicas, a verdade é que, muitas vezes, devido a comportamentos conformistas, de competição, comparação ou necessidade de inserção, os adolescentes se entregam ao álcool "de corpo e alma". Analisando, de forma breve, alguns dos mecanismos indutores dos comportamentos alcoolizantes entre os adolescentes e jovens vemos, entre outros, a pressão do grupo de pares, a imitação comportamental, o conformismo adaptativo e a liderança no seio do grupo.

\section{Interação grupal}

As interações grupais visam aos indivíduos atingirem objetivos comuns e solidariamente atuam entre si. Nessa dinâmica pode surgir um processo de influência dentro 
do grupo que leva no indivíduo a reconciliar seu comportamento ao grupo. Os modelos de condutas e papéis sociais são aprendidos e assimilados e o grau de obediência que implicam em menor ou maior grau nas regras de grupo informais. Nessa direção o consumo de drogas toma lugar importante, e o não cumprimento pode levar à repressão senão à rejeição.

Lewina apud Sousa et al. (2008, p. 47-48), afirma que

\begin{abstract}
A interação grupal deriva dos comportamentos dos indivíduos entre si e implica a influência mútua dos seus comportamentos dentro do grupo. Esta interação pode passar pela adoção de condutas e expressões linguísticas próprias, que só ganham dimensão no grupo e que servem para distingui-lo de outros grupos.
\end{abstract}

\title{
Imitação comportamental
}

A adolescência se refere à idade mais saliente aos comportamentos estereotipados e conformistas, visto que nela se verifica uma grande suscetibilidade nas influências externas e, principalmente dos pares. Portanto, os jovens e adolescentes chegam a consumir drogas por seguir o ritmo dos elementos considerados influentes do grupo e por este comportamento constitui o processo de imitação como acima se referência.

Sousa et al. (2008) diz que o conformismo com o grupo, expresso na atitude de imitação comportamental é, na sua forma mais simples, a adoção dos mesmos comportamentos, atitudes e valores por parte de um indivíduo, que os outros membros do grupo adotam, mesmo contrariando os seus próprios princípios. Os autores referem ainda que estudos de Bandura, realizados em 1965, concluíram que a imitação é um processo de aprendizagem, feita por meio da observação, que acompanha o ser humano ao longo de toda a sua vida. Embora esteja muito presente na infância, a imitação tem grande importância na adolescência. Nessa fase de interação grupal por excelência, o adolescente pode ser induzido, por meio da imitação, a consumir droga. Se, ao fazê-lo, os resultados para o indivíduo forem esperados, como por exemplo, ser reconhecido pelo grupo pelo fato de ter conseguido consumir, então o adolescente passa a prever que, agindo daquela forma, obterá determinado efeito, saindo o seu comportamento reforçado. 


\section{Conformismo adaptativo}

Importa salientar que o processo de influência social, assim como o comportamento de grupo não são regras sem exceção, portanto, os grupos são organizados por pessoas para uma interação entre si e os seus valores. O comportamento e a personalidade continuam a ter impacto, muitas vezes, e não são abandonados em favor do grupo.

Dessa feita, muitas vezes as atitudes dos adolescentes e jovens são condicionadas e influenciadas pelos comportamentos de grupo. Assim, os indivíduos possuem todas as vivências e educação de forma individual que mais tarde se tornarão mais ou menos influenciáveis. A ligação com a família pode condicionar a adoção de uma posição individual em relação ao seu envolvimento com o grupo.

Sousa et al. (2008) afirmam que a adolescência é, por excelência, a fase grupal da vida do indivíduo, em que este necessita estar inserido num grupo de amigos. É no seio desses grupos que irá se desenvolver e adquirir aptidões fundamentais para a sua vida futura profissional, social, sexual e afetiva. Contudo, é também no seio desses grupos que se geram certos comportamentos, mais ou menos positivos, e interações diversas que vale a pena analisar e tentar estabelecer um elo com o consumo de álcool. Assim, em contexto de diversão, interações, festas e saídas, caracterizadas muitas vezes por processos de influência social, podem incentivar o indivíduo a se envolver em drogas.

O álcool e outras drogas trazem, em geral, graves consequências para o indivíduo, quer em nível físico, sendo fator de risco para várias doenças, quer m nível da sua vida social e relacional. E se os problemas físicos e psicológicos, ocasionados pelos consumidores, são graves em qualquer idade, eles se tornam potencialmente mais graves num organismo em formação e crescimento, como é o caso dos jovens e adolescentes.

\section{Efeitos orgânicos do consumo de álcool e outras drogas}

O álcool e outras drogas consumidas entram e circulam nas veias sanguíneas, passando pelo fígado onde começa o serviço de metabolismo. O consumo de substâncias psicopáticas, o álcool em particular, é eliminado pelos rins e os resíduos voltam eventualmente ao fígado que serão transformados em gás carbónico e água, depois são expelidos pelos pulmões.

O estudo elaborado mais recente, de Ferreira, Borges e Filho (apud Sousa, 2008), 
sistematiza os principais efeitos derivados da ingestão desregrada de álcool, classificando-os da seguinte forma: (1) complicações cardiovasculares; (2) efeitos em nível hepático; (3) efeitos neurológicos; (4) efeitos gastrointestinais; (5) alterações endócrinas e metabólicas, e (6) alterações hematológicas. No sistema cardiovascular, doses elevadas de álcool provocam lesões no coração, provocando arritmias e outros problemas, tais como tromboses e derrames consequentes. É relativamente comum a ocorrência de um AVC, após a ingestão de grande quantidade de bebidas alcoólicas. Com o tempo, o álcool pode provocar micro lesões no miocárdio e causar o aumento da pressão arterial, "podendo degenerar em cardiomiopatia congestiva com dispneia progressiva, com intolerância ao esforço, edemas ou outros sinais congestivos".

Para Almeida et al. (2014, p. 66)

Os seus efeitos repercutem na neuroquímica cerebral, em pior ajustamento social e no retardo do desenvolvimento de suas habilidades, já que um adolescente ainda está em processo de maturação em termos biológicos, sociais, pessoais e emocionais. Durante a adolescência o córtex pré-frontal ainda está em desenvolvimento, podendo o uso do álcool afetar uma série de habilidades que o adolescente necessita desenvolver e que são mediadas por este circuito.

\section{Efeitos psicossociais do consumo de álcool e outras drogas}

O uso do álcool e outras drogas traz a todos níveis inúmeras consequências desastrosas. Os acidentes de viação, de trânsito, de violência doméstica, abuso de menores e sexual, de trabalho, de homicídios, desmembramento familiar, de baixo rendimento pedagógico e deficiente relacionamento com colegas. Essas e outras consequências comprometem o futuro do indivíduo, da família e de um país em geral.

Para Cavalcante, Alves e Barroso (2008, p. 557) "o consumo de álcool em excesso pelo adolescente traz várias consequências graves para sua saúde, evidenciando-se que esta droga socialmente aceita é a porta de entrada para o consumo e o vício em outras drogas, ditas ilícitas".

As escolas têm vivenciado um aumento da agressividade e violência. O uso abusivo de drogas psicotrópicas retroalimenta a violência e está associado com bullying para ambos sexos. Também, os jovens que fazem esse uso apresentam maior agressividade, estão menos 
predispostos ao estudo e são mais desatentos (ELICKER et al., 2015, p. 400).

\title{
Implicações escolares do consumo de álcool e outras drogas
}

O consumo do álcool pelos adolescentes enquanto alunos compromete o seu rendimento escolar desde cedo. A ingestão do álcool traz consigo as repercussões diretas a curto, médio e longo prazo. A diminuição do rendimento escolar, assim como os comportamentos de risco (à saúde) são os problemas que surgem a curto prazo. Assim, a personalidade dos adolescentes que consomem o álcool poderá ter interferência no seu desenvolvimento cognitivo e físico.

\begin{abstract}
Classe social, escolaridade, vínculo com a escola e a ocorrência de reprovações escolares estiveram associadas a consumo de tabaco e drogas ilícitas, prejuízo no desempenho e baixa frequência escolar. 0 consumo de drogas tem maior prevalência entre grupos com menor escolaridade (ELICKER et al., 2015, p. 400).
\end{abstract}

No entanto, olhando a imaturidade orgânica e cognitiva do adolescente consumidor, as implicações são várias, desde a sua saúde, frequência e envolvimento nas atividades escolares e o relacionamento com os pares, os professores e até com a família. Portanto, muitos adolescentes se tornam agressivos e desrespeitam as normas de convivência na escola, perdem muitas aulas e, às vezes, chegam a desistir. Em suma, o consumo de drogas conduz ao baixo aproveitamento escolar dos adolescentes praticantes.

\section{Estratégias de intervenção psicossocial ao consumo de drogas nas escolas}

Pelo nível de risco que os adolescentes consumidores de álcool e outras drogas que Ihes esperam, sugere-se como estratégias para mitigar o fenómeno:

1 - Proibição de venda de álcool e outras drogas em cantinas e barracas ao redor de escolas

Esta estratégia é aplicável se for operacionalizado o Decreto № 54-2013, de 7 de outubro (MOÇAMBIQUE, 2013) e da Resolução n. 15/2003, de 4 de abril (MOÇAMBIQUE, 2003). As escolas, em coordenação com os municípios, devem garantir a fiscalização e penalização dos agentes comerciais que mantêm a venda de álcool e outras drogas nos arredores das escolas e aos menores. Portanto, será mais fácil gerir aspectos oportunistas 
quando os fatores de risco estiverem longe dos infratores.

2 - Promoção de ciclos de palestras nas escolas e nas comunidades

A escola, os profissionais de saúde e os agentes políticos devem promover ciclos de palestras e teatros junto às escolas e comunidades sobre os prejuízos de consumo de drogas enquanto adolescentes e divulgar a lei que proíbe a venda de álcool aos menores. As pessoas conhecem os perigos que as drogam trazem no meio social, contudo, a disseminação por meio de palestras e encontros com a comunidade vai conscientizá-la sobre a responsabilidade social.

Em órgãos de informação pública como rádio, televisão, jornais e outros, além das belas publicidades sobre o álcool e/ou tabaco, deve se encontrar um espaço em que possam abordar questões de riscos e prejuízos do consumo de drogas. Esse espaço seria oportuno para divulgar o decreto no 54-2013, de 07 de outubro (MOÇAMBIQUE, 2013) e da Resolução n¹5/2003 (MOÇAMBIQUE, 2003), de 4 de abril, e outras informações necessárias a respeito de consumo de drogas pelos adolescentes nas escolas.

3 - Criação de gabinetes de aconselhamento psicológico junto às escolas

Dado o grau de profissionais de psicologia formados em muitas universidades moçambicanas e fora do país, sugere-se que haja nas escolas gabinetes de atendimento psicológico. A presença do psicólogo sempre foi importante, além de questões de drogas que se vêm discutindo, têm surgido nas escolas enúmeras situações que exigem um profissional de psicologia para intervir. Junto com os profissionais de saúde, o psicólogo diagnostica e intervém ao tratamento em casos mais graves. Em todo caso, o acompanhamento psicológico vai ajudar o ajustamento comportamental do adolescente consumidor.

Para Lima, Dimenstein e Macedo (2015), perante casos de consumo abusivo de álcool e drogas, o psicólogo pode: acompanhar mais intensivamente os casos identificados pela equipe da estratégia saúde da família com padrão de uso regular e abusivo e com prejuízos à funcionalidade, exposição a riscos, danos e vulnerabilidades; trabalhar a partir do manejo do vínculo, da escuta qualificada e do acolhimento do sujeito em suas necessidades e singularidades para minimizar as resistências e oferecer abordagem direta e assertiva que motive o indivíduo e a família a procurarem ajuda.

4 - Penalizações aos alunos e professores consumidores 
As escolas e qualquer organização trabalham segundo princípios e normas préestabelecidas. O consumo de álcool e outras drogas em recinto escolar e/ou apresentação dos utentes da mesma sob efeito de drogas deve ser objeto de penalização. Devido à incapacidade que as drogas criam aos consumidores, tanto o professor como o aluno devem se abster ao consumo, garantindo bom exemplo e responsabilidade por um lado e, disponibilidade psicossocial para aprendizagem, por outro.

\section{Considerações finais}

Em virtude das constatações observadas e das notícias apresentadas sobre o cotidiano dos adolescentes e jovens nas escolas face ao consumo de drogas, levantamos as questões de reflexão: o que fazer com alunos consumidores de drogas nas escolas? O que fazer com as barracas e cantinas que vendem algumas drogas ao redor das escolas? O que fazem os nossos psicólogos educacionais, escolares, assistentes sociais que as universidades moçambicanas formam anualmente e que poderiam intervir nesses assuntos? Como evitar a propagação do fenômeno para a nova geração? Onde está a figura dos pais e encarregados de educação, do professor, membros de Conselho de Escola e da comunidade em geral, sobre os alunos consumidores de drogas na escola e fora dela?

Os alunos viciados hoje e os principiantes são nossos filhos, irmãos, vizinhos e amigos dos nossos filhos que precisam de um urgente apoio, uma orientação e aconselhamento para se integrar ao meio social e continuar com a vida saudável. Os psicólogos formados, muitos deles, estão a leccionar as disciplinas que nem dizem respeito ao seu potencial e habilidades profissionais, como é o caso de Português, Geografia, História, Matemática, para os que conseguiram; sem contar com outros em lista de espera para conseguirem um espaço para aplicar a sua teoria.

O combate de consumo de álcool e outras drogas nas escolas, deve ser tarefa de todos, desde os pais e encarregados de educação, membros do Conselho de Direção, professores e a comunidade em geral. Portanto, o adolescente (aluno) que consome droga, adquire o produto na comunidade. Outrossim, as autoridades governamentais em coordenação com as direções das escolas, devem desencorajar a instalação de barracas e cantinas nas escolas ou ao redor delas. Ainda, deve-se promover um sistema de palestras sobre os riscos do consumo 
de drogas nas escolas e pelos adolescentes. É oportuno que o Sistema Educativo potencie nas escolas serviços de atendimento psicológico com suporte dos profissionais que o país anualmente forma. Ainda, o Governo, por meio da mídia e palestras deve divulgar as informações e todas restrições do Decreto n 4-2013, de 07 de outubro (MOÇAMBIQUE, 2013) e da Resolução n¹5/2003, de 4 de abril (MOÇAMBIQUE, 2003) e em outros escritos.

\section{Referências}

ALMEIDA, R. M. M. et al. Uso de álcool, drogas, níveis de impulsividade e agressividade em adolescentes do Rio Grande do Sul. Psico, Porto Alegre, v. 45, n. 1, p. 65-72, 2014. Disponível em: $\leq$ http://revistaseletronicas.pucrs.br/ojs/index.php/revistapsico/article/view/12727/1144 z. Acesso em: 19 abr. 2018.

BAPTISTA, R. Representação social do consumo de bebidas alcoólicas em estudantes do ensino superior de Coimbra. 2004. Dissertação (Mestrado) - Instituto Superior Miguel Torga, Coimbra - PT, 2004.

CARNEIRO, H. Transformações da palavra "droga": das especiarias coloniais ao proibicionismo contemporâneo. In: VENÂNCIO, R. P.; CARNEIRO, H. (org.). Álcool e drogas na história do Brasil. São Paulo: Alameda, 2005. p. 11-27.

CAVALCANTE, M. B. P. T.; ALVES, M. D. S.; BARROSO, M. G. T. Adolescência, álcool e drogas: uma revisão na perspectiva da promoção da saúde. Esc. Anna Nery Ver. Enferm., Ceará, v. 12, n. 3, p. 555-559, 2008. Disponível em: <http://www.scielo.br/pdf/ean/v12n3/v12n3a24>. Acesso em: 19 abr. 2018.

ELICKER, E. et al. Uso de álcool, tabaco e outras drogas por adolescentes escolares de Porto Velho - RO, Brasil. Epidemiol. Serv. Saúde, Brasília, v. 24, n. 3, p. 399-410, 2015. Disponível em: <http://www.scielo.br/pdf/ress/v24n3/2237-9622-ress-24-03-00399.pdf >. Acesso em: 28 abr. 2018.

LIMA, A. I. O.; DIMENSTEIN, M.; MACEDO, J. P. Consumo de álcool e drogas e o trabalho do psicólogo no núcleo de apoio à saúde da família. Psicologia em Pesquisa, UFJF, v. 9, n. 2, p. 188-197, 2015. Disponível em: <pepsic. bsalud. org/pepsipesq/v9n2a09.pdf>. Acesso em 27 fev. 2019.

MARTINS, I. P. S. G.; QUADROS, E. A. O consumo de bebidas alcoólicas na adolescência e suas consequências na aprendizagem. Cadernos PDE, v. 1, n. 1, p. 1-20, 2013. Disponível em: $<$ http://www.diaadiaeducacao.pr.gov.br/portals/cadernospde/pdebusca/producoes pde/20 13/2013 fafipar pe>. Acesso em: 27 abr. 2018.

MOÇAMBIQUE, REPÚBLICA DE. Portal do Governo de Moçambique. Jornal Notícias Online Publicado em Quarta, 23 Março 2016. Disponível em:

$<$ http://www.portaldogoverno.gov.mz/por/Imprensa/Noticias/Consumo-de-alcool-nasescolas-preocupa-sect>. Acesso em: 27 abr. 2018.

MOÇAMBIQUE, REPÚBLICA DE. Resolução n. 15/2003 de 4 de abril. Política e Estratégia de 
Prevenção e Combate à Droga. Boletim da República: Publicação Oficial da República de Moçambique. Série I, n. 20, p. 153-159. Disponível em:

<http://www.portaldogoverno.gov.mz/por/content/download/1514/12657/version/1/file/P olitica+de+Combat>. Acesso em: 27 abr. 2018.

MOÇAMBIQUE, REPÚBLICA DE. Decreto n. 54 de 07 de outubro de 2013. Regulamento Sobre o Controlo de Produção, Comercialização e Consumo de Bebidas Alcoólicas. Boletim da República: Publicação Oficial da República de Moçambique. Série I, n. 80, p. 741.

Disponível em: <http://www.at.gov.mz/por/Media/Files/Decreto-n1-54-2013-de-07-deOutubro-1a-serie-n1-80>. Acesso em: 27 abr. 2018.

MOÇAMBIQUE, REPÚBLICA DE. Portal do Governo de Moçambique. Jornal de Notícias Online, publicado em 10 de Novembro de 2015, Consumo de drogas e álcool nas escolas preocupa autoridades de Nampula. Disponível em: $<$ http://www.dw.com/pt-002/consumode-drogas-e-\%C3\%A1lcool-nas-escolas-preocupa-autoridades-de-nampula/a-18841540>. Acesso em: 18 abr. 2018.

PORTALANGOLAP, Primeiro-ministro recomenda combate à droga com os recursos disponíveis, 24 fevereiro 2018. Disponível em:

<http://www.angop.ao/angola/pt pt/noticias/africa/2018/1/8/Mocambique-Primeiroministro-recomenda-co>. Acesso em: 19 abr. 2018.

SILVA, I. A. Consumo de bebidas alcoólicas por estudantes do ensino médio e características do grupo de pares. Marília, 2010. Dissertação (Mestrado em Educação) Faculdade de Filosofia e Ciências, Universidade Estadual Paulista (Unesp), 2010. São Paulo, 2010. Disponível em:

<https://www.marilia.unesp.br/Home/Posgraduacao/Educacao/Dissertacoes/silva ia me mar.pdf>. Acesso em: 27 abr. 2018.

SOUSA, F. C. et al. O consumo de bebidas alcoólicas na população escolar juvenil, Lisboa: 2008.

WILLHELM, A. R. et al. Consumo de Álcool na Adolescência e Relação com Uso Excessivo de Bebidas Alcóolicas dos Pais: Estudantes de Quatro Escolas de Porto Alegre. Psico, Porto Alegre, v. 46, n. 2, p. 208-216, 2015. Disponível em:

$<$ https://www.researchgate.net/publication/283042483 Consumo de Alcool na Adolesce ncia e Relacao co>. Acesso em: 27 abr. 2018.

Recebido em: 22/09/2018

Aprovado em: 15/03/2019 